\title{
Focus-group Discussion on Smoking Cessation Methods and its Awareness among Interns and Home Guards
}

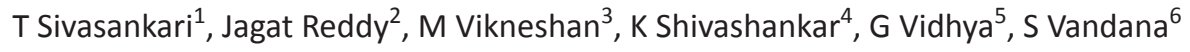

\begin{abstract}
Smoking is a major public health problem. It is a serious concern in both developed and developing countries. There are 1.3 billion smokers around the world. Furthermore, 5 million people die worldwide from smoking each year. ${ }^{1}$ Health knowledge about the ill effects of smoking is very important factor to motivate smokers to quit smoking. Dental institutions provide very good platform to educate budding dentists to inculcate the habit of tobacco cessation counseling, including nicotine replacement therapy (NRT).

Keywords: Counseling, Nicotine replacement therapy, Smoking.

Journal of Scientific Dentistry (2019): 10.5005/jp-journals-10083-0910
\end{abstract}

\section{INTRODUCTION}

A focus-group discussion involves gathering people from similar backgrounds or experiences together and discusses a specific topic of interest. It is a form of qualitative research where they are questioned about their perceptions, attitudes, beliefs, opinion, and ideas with regard to their habit. ${ }^{2}$ Smoking cessation counseling is of major importance for future healthcare providers who currently are our interns. The quality of health is strongly influenced by lifestylerelated habits. Because lifestyle-related habits play a central role in influencing the state of health of each individual, the effectiveness of future treatments may greatly depend on the extent to which patients are involved in improving their health by actively changing their habits. ${ }^{3}$ According to relevant published literature, a variety of behavior therapies ranging from simple counseling offered by a oral physician or another healthcare providers or much more extensive therapy offered by counselors have all been shown to be effective for smoking cessation. ${ }^{4,5}$ Basic knowledge of certain skills is required to provide effective counseling for smoking cessation. This discussion mainly focuses on awareness of various tobacco cessation methods and its awareness among interns and home guards.

A focus-group discussion was planned and extended where the interns were primed how to carry out tobacco cessation program and the home guards with the habit were counseled for the same by the interns.

\section{Materials and Methods}

A focus-group discussion was conducted; 10-15 participants participated in two programs. In first group, we had discussion about the habit cessation counseling. In second group, we discussed about the ill effects of tobacco. A questionnaire was prepared for the second program with the home guards to ask about the ill effects of smoking and various habit cessation methods.

\section{Intern's Focus Group}

Two groups of interns participated. The first group of intern had completed the tobacco cessation center (TCC) posting and the second group of intern was scheduled for the posting. Both the
1,2,6 Department of Oral medicine and Radiology, Indira Gandhi Institute of Dental Sciences, Sri Balaji Vidyapeeth (a Deemed University), Pillayarkuppam, Puducherry, India

${ }^{3-5}$ Department of Public Health Dentistry, Indira Gandhi Institute of Dental Sciences (a Deemed University), Pillayarkuppam, Puducherry, India

Corresponding Author: T Sivasankari, Department of Oral Medicine and Radiology, Indira Gandhi Institute of Dental Sciences, Sri Balaji Vidyapeeth (a Deemed University), Puducherry, India, Phone: +91 9443877381, e-mail: sankarisenthil10@yahoo.com

How to cite this article: Sivasankari T, Reddy J, Vikneshan $M$, Shivashankar K, Vidhya G, Vandana S. Focus-group Discussion on Smoking Cessation Methods and its Awareness among Interns and Home Guards. J Sci Den 2019;9(2):41-42.

Source of support: Nil

Conflict of interest: None

groups engaged in a discussion about their experiences and challenges faced during the posting while the second group had taken a keen note on the challenges faced by the group which completed their posting.

The following themes were discussed.

\section{Theme 1: Perceptions about Psychiatry Education}

We have asked the interns about their opinions and perceptions toward habit cessation counseling. Many students shared their views and skills gained during habit cessation counseling. They learnt to facilitate and communicate with the patient which gave them good confidence. Some students could communicate better with the patients, while others experienced difficulties on how to deal with patient's resistance and reactions, such as how to tackle and gain patient confidence which will in turn help the patient believe in the TCC program. Some students expressed a need for further training and support to develop their efficiency in delivering a counseling more effectively. In addition, to further support their efficiency and confidence regarding skills, students requested more training and support in dealing with individual differences and personality skills. 
They highlighted the need for communication and counseling skills to be part of their training and also identified a need for skilledbased learning such as "how to convince patients to change, and the supportive and directive ways to bring about change in patients."

\section{Theme 2: Nicotine Replacement Therapy}

Most of the interns are not aware of the various nicotine replacement therapies (NRTs) available. They need to gain knowledge about the various forms and dosages available. Professional training and enrichment programs are required to increase their knowledge, understanding, and practices which will help in prescription writing of various NRTs. The student enrichment program on NRT will help students achieve the above target.

\section{Focus-group Discussion for Home Guards}

The guards were seated comfortably and a formal introduction was given about the "TCC" program. They were segregated into two groups with the first group being the nonsmokers and the others with smokers who were quizzed on the habit and also were discussed upon the reason which motivated them to quit the habit. The interns then spoke about the smoking cessation and counseling methods with the guards. Further both the groups discussed about habit cessation methods individually when nonsmokers were asked to detail and voice out there opinion regarding smoking.

The following themes were deduced from the discussion.

\section{Theme 1: III Effects of Smoking}

Majority of the smokers believe that smoking causes lung cancer and heart problems. Their knowledge on ill effects of smoking on over health was limited. Then a highlight about the ill effects of smoking causes periodontitis, smoker's palate, and oral cancer was discussed.

\section{Theme 2: Reasons for Smoking}

The most common reason cited for smoking was a relief in stress they experience. Most of the guards smoked Beedi due to their low socioeconomic status. When they were discussed about the ill effects of smoking, their concern to quit the habit was expressed.

\section{Theme 3: Reasons for Not Smoking}

When asked about reasons to quit smoking or never to smoke, most participants said that cigarette smoking is unhealthy, and they had a general understanding that it can lead to heart and lung problems and also cancer. In contrast, nonsmokers frequently and spontaneously cited health concerns as an important reason why they do not smoke.

\section{Theme 4: Strategies for Quitting and Maintaining Abstinence}

We asked smokers and nonsmokers about strategies they have used to quit smoking. Their answers emphasized the combined importance of motivation, information, and sustained support. In addition to that, we explained about pharmacological substitutes and home remedies to quit smoking.

The security guards were more enthusiastic in participating in focus-group discussion. They were very comfortable in sharing their experiences with the doctors. In the home guards session, we discussed their behavior and attitude toward cessation of the habit and they were explained about the ill effects of smoking on their health and finance.

\section{Conclusion}

Students have shown willingness to perform smoking cessation interventions. It is apparent that more skills and knowledge are required to gain confidence in engaging with the patients. To reduce the barriers in the performance of habit cessation counseling, students should benefit from practical training that would address ways to teach them practical strategies that would aid their interpersonal skills. This would increase confidence and ability to bring about change in students. Long-term change in student behavior (providing counseling) toward their patients for the benefit of their patients is expected.

\section{References}

1. Nyumba TO, Wilson K, DerrickCJ, Mukherjee N. The use of focus group discussion methodology: Insights from two decades of application in conservation. Methods Ecol Evol 2018;9(1):20-32. DOI: 10.1111/2041210X.12860.

2. Dawood OT, Rashan MA, Hassali MA, Saleem F. Knowledge and perception about health risks of cigarette smoking among Iraqi smokers. J Pharm Bioallied Sci 2016;8(2):146-151. DOI: 10.4103/09757406.171738 .

3. Shah S, Rath H, Sharma G. Knowledge, attitude and practices of institution-based dentist toward nicotine replacement therapy. Indian J Dent Res 2017;28(6):629-636. DOI: 10.4103/ijdr.JJDR_231_17.

4. Ajagannanavar SL, Alshahrani OA, Jhugroo C, Tashery MT, Mathews J, Chavan K. Knowledge and perceptions regarding nicotine replacement therapy among dental students in Karnataka. J Int Oral Health 2015;7(7):98-101.

5. Khalaf ME, Curtin S, Trace A. Perception and attitudes of dental students towards their role in the delivery of a brief smoking cessation intervention. Med Princ Pract 2019;8:1-6. DOI: 10.1159/000501420. 